\title{
Shear wave elastography in the evaluation of level VI lymph nodes in papillary thyroid carcinoma: combined with gray-scale ultrasound ex vivo
}

\author{
Chang Wanying ${ }^{1+}$, Tang Lei ${ }^{1+}$, Lu Caiwei ${ }^{2}$, Wu Min² and Chen Man ${ }^{1 *}$ (D)
}

\begin{abstract}
Background: The evaluation of cervical lymph nodes is very important for patients with papillary thyroid carcinoma (PTC). Conventional ultrasound is recommended to assess the status of cervical lymph nodes but the diagnostic performance is not satisfying especially in level VI lymph nodes. Recently, shear wave elastography has shown great potential in diagnosis. Therefore, this study aimed at exploring the value of shear wave elastography in ultrasound evaluation for level VI lymph nodes in papillary thyroid carcinoma. Because Hashimoto's thyroiditis may influence the diagnostic performance, a subgroup was also analysed that included only lymph nodes from PTC without Hashimoto's thyroiditis.
\end{abstract}

Methods: Eighty-Seven level VI lymph nodes from 22 consecutive patients with papillary thyroid carcinoma were evaluated by gray-scale ultrasound and SWE in condition of ex vivo before rapid frozen section. Gray-scale ultrasound and shear wave elastography indexes of metastatic and non-metastatic lymph nodes were evaluated by statistical analysis separately in all patients and in patients without Hashimoto's thyroiditis. Indexes included long diameter, short diameter, short-to-long diameter ratio $\left(S / L\right.$ ratio), $E_{\text {mean, }} E_{\min ,} E_{\max }$ and $E_{S D}$. The rapid frozen section result of each lymph node was used as gold standard to evaluate the diagnostic performance of gray-scale ultrasound and combination method which combined gray-scale ultrasound and SWE.

Results: In all patients, significant indexes included short diameter $(p=0.009), \mathrm{S} / \mathrm{L}$ ratio $(p=0.003), \mathrm{E}_{\max }(p=0.016)$ and $\mathrm{E}_{S \mathrm{D}}(p=0.006)$. In patients without Hashimoto's thyroiditis, significant indexes included short diameter $(p=0.002), \mathrm{S} / \mathrm{L}$ ratio $(p=0.003), E_{\text {mean }}(p=0.030), E_{\max }(p<0.001)$ and $E_{S D}(p=0.001)$. Combining gray-scale ultrasound with $S W E$, combination method had higher AUC than gray-scale ultrasound both in all patients (0.887 vs 0.841 ) and patients without Hashimoto's thyroiditis (0.925 vs 0.866). Gray-scale ultrasound had higher AUC in patients without Hashimoto's thyroiditis than in all patients (0.866 vs 0.841 ), which was the same with combination method ( 0.925 vs 0.887 ).

Conclusion: Shear wave elastography can provide additional information for ultrasound evaluation of level VI lymph nodes in papillary thyroid carcinoma, especially in papillary thyroid carcinoma without Hashimoto's thyroiditis.

Keywords: Shear wave elastography, Level VI lymph nodes, Papillary thyroid carcinoma, Gray-scale ultrasound

\footnotetext{
*Correspondence: maggiech3138@126.com

${ }^{+}$Chang Wanying and Tang Lei contributed equally to this work.

'Department of Diagnostic Ultrasound, Tong Ren Hospital, Shanghai Jiao

Tong University School of Medicine, No. 1111 Xian Xia Road, Shanghai

200336, China

Full list of author information is available at the end of the article
}

(c) The Author(s). 2018 Open Access This article is distributed under the terms of the Creative Commons Attribution 4.0 International License (http://creativecommons.org/licenses/by/4.0/), which permits unrestricted use, distribution, and reproduction in any medium, provided you give appropriate credit to the original author(s) and the source, provide a link to the Creative Commons license, and indicate if changes were made. The Creative Commons Public Domain Dedication waiver (http://creativecommons.org/publicdomain/zero/1.0/) applies to the data made available in this article, unless otherwise stated. 


\section{Background}

The incidence of thyroid carcinoma is steadily increasing in recent years [1]. Papillary thyroid carcinoma (PTC) is the most common histological type and tends to metastasize to cervical lymph nodes [2]. Cervical lymph node metastasis of PTC is one of the important risk factor for tumor recurrence and generally occurs firstly in the level VI lymph nodes which are also called central cervical lymph nodes [3, 4]. Therefore, level VI lymph nodes were also considered as sentinel lymph nodes whose status can predict lateral involvement in PTC and impact the determination of tailoring treatment for patients [5]. Thus, the evaluation of level VI lymph nodes status is essential.

Preoperative Ultrasound for cervical lymph nodes, including central and lateral compartments lymph nodes, is strongly recommended by American Thyroid Association (ATA) to all patients undergoing thyroidectomy due to malignant or suspicious thyroid nodules [5]. However, the diagnostic performance of conventional ultrasound in cervical lymph nodes is not satisfying, especially in level VI lymph nodes [6,7]. Other imaging techniques may provide additional information to help diagnosis.

Shear wave elastography (SWE) is a kind of ultrasound elastography which can quantitatively measure tissue elasticity and is a good complementary tool to B-mode ultrasound [8]. It has showed bright prospect in the evaluation of cervical lymph nodes due to its high reproducibility and high diagnostic performance (especially in group of sub-centimeter cervical lymph nodes) [9]. Central cervical lymph nodes are much smaller than lateral lymph nodes and their mean size is less than $1 \mathrm{~cm}$ [10], which makes it possible that central cervical lymph nodes might benefit more from the help of SWE. However, the imaging quality and reliability of ultrasound may be influenced by the complicated anatomic structure in central neck such as clavicle, sternum, trachea, carotid artery and so on [11]. To avoid these influences in vivo, lymph nodes were evaluated ex vivo in our study. The aim of this study was to investigate if the SWE could help to differentiate metastatic form non-metastatic level VI lymph nodes in a pre-clinic ex-vivo model in patients with PTC. Because the Hashimoto's thyroiditis might influence the diagnostic performance [12], lymph nodes from patients without Hashimoto's thyroiditis were also analyzed separately.

\section{Methods}

\section{Specimens}

From April to May 2017, we collected and scanned 30 consecutive patients' fresh cervical surgical specimens before rapid frozen sections. All these patients were underwent thyroid surgery and regional cervical lymph nodes resection in our hospital because of confirmed or suspicious malignant thyroid nodules. Among them, 8 patients were excluded because of following reasons: 1 . primary thyroid lesions were confirmed to be benign in pathology (5 patients); 2. There were no obvious lymph nodes in ultrasound imaging of the specimens and then pathologic results confirmed that there were no tumor metastases (2 patients); 3. SWE was performed but failed because of the poor quality of SWE (1 patient). Finally, total of 87 level VI lymph nodes from 22 patients, $17 \mathrm{fe}$ males and 5 males, were enrolled in this study, including 14 level VI lymph nodes from 3 patients with papillary thyroid microcarcinoma (PTMC) and Hashimoto's thyroiditis, 37 level VI lymph nodes from 7 patients with PTC, and 36 level VI lymph nodes from 12 patients with PTMC. Mean age of these patients was $45.6 \pm 13.3$ (range 25-70) y. This study was approved by the Independent Ethics Committee of Shanghai Tongren Hospital. All informed consents were obtained from patients.

\section{Ultrasound examination}

All the fresh cervical lymph nodes surgical specimens were scanned by ultrasound before underwent intraoperative frozen sections. Gray-scale ultrasound and SWE were performed using the Aixplore US system (SuperSonic Imaging, Aix-en-Provence, France) with a $15-4-\mathrm{MHz}$ linear-array transducer (SuperLinear SL15-4). Specimens were placed between two gel pads that were putted together in a quadrate glass container (Fig. 1). Ultrasonic coupling agent was used to eliminate the clearance between specimens and gel pads. Gray-scale ultrasound and SWE were performed respectively on entire specimen and corresponding image data were stored as short video files for the sake of subsequent analysis. When performing SWE, probe was placed on the gel pad as lightly as possible to avoid pressure artifact. Imaging quality was considered to be poor when there were less than $80 \%$ color signal within the sample

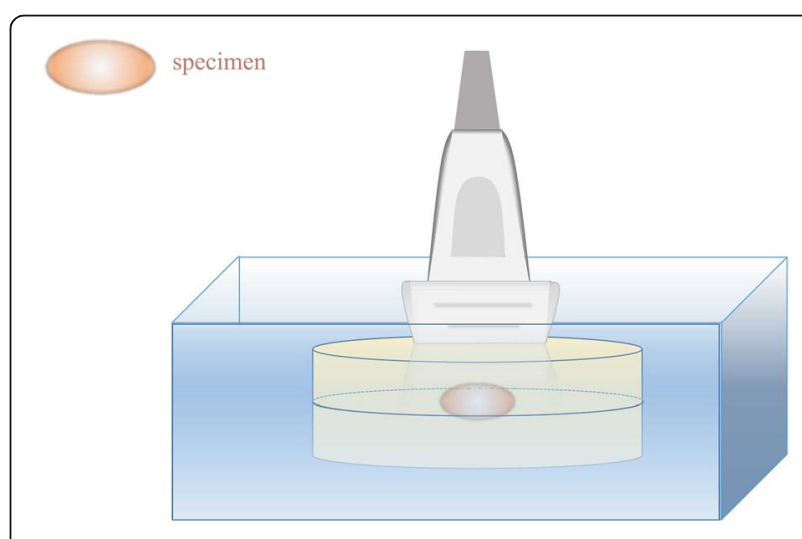

Fig. 1 The diagram of ex vivo ultrasound scanning for specimens 
frame. Sample frame was selected to ensure that entire specimen was in the central of frame. If the specimen was too big to contain in the sample frame completely, second scan was needed to complete it. All the lymph nodes were evaluated by one radiologist.

\section{Images analysis}

US assessment was performed blind of pre-operative staging and pathological staging. The short diameter and long diameter of lymph nodes were measured in their largest section on gray-scale ultrasound and then short-to-long diameter ratio ( $\mathrm{S} / \mathrm{L}$ ratio) was calculated. Elastography indexes, including $E_{\text {mean }}, E_{\min }, E_{\max }$ and $E_{S D}$, were measured by manually depicting a region of interest (ROI) in which only entire lymph node was contained (Figs. 2, 3 and 4). The four elastography indexes of $E_{\text {mean }}, E_{\min }, E_{\max }$ and $E_{S D}$ respectively refer to the mean value, minimum value, maximum value and the standard deviation of the Young modulus (represent for elastic modulus) in the ROI.

Intraoperative frozen section results were considered as reference standard to evaluate the diagnostic value of each index (including three gray-scale ultrasound indexes and four SWE indexes). All frozen section results in our study were proved to be consistent with subsequently paraffin section results. Significant indexes and their best cutoff values were determined respectively in all patients and in patients without Hashimoto's thyroiditis by statistical analysis. Then, a score of 0 or 1 was given for each significant index according to whether they were suspicious for malignancy (score was 1 when it was suspicious for malignancy). Overall scores of gray-scale ultrasound alone and combination of gray-scale ultrasound and SWE were gained respectively to evaluated lymph nodes status.

\section{Statistical analysis}

Statistical analyses were performed with IBM SPSS Statistics version 20.0 software. Quantitative dates were expressed as mean \pm standard deviation $(\mathrm{Sd})$ when normal distribution was achieved. Continuous variables were analyzed by t-tests and a value of $p<0.05$ was considered statistically significant. Receiver operating characteristic (ROC) curves were plotted to assess the diagnostic performance and the best cutoff value of each significant index were determined by

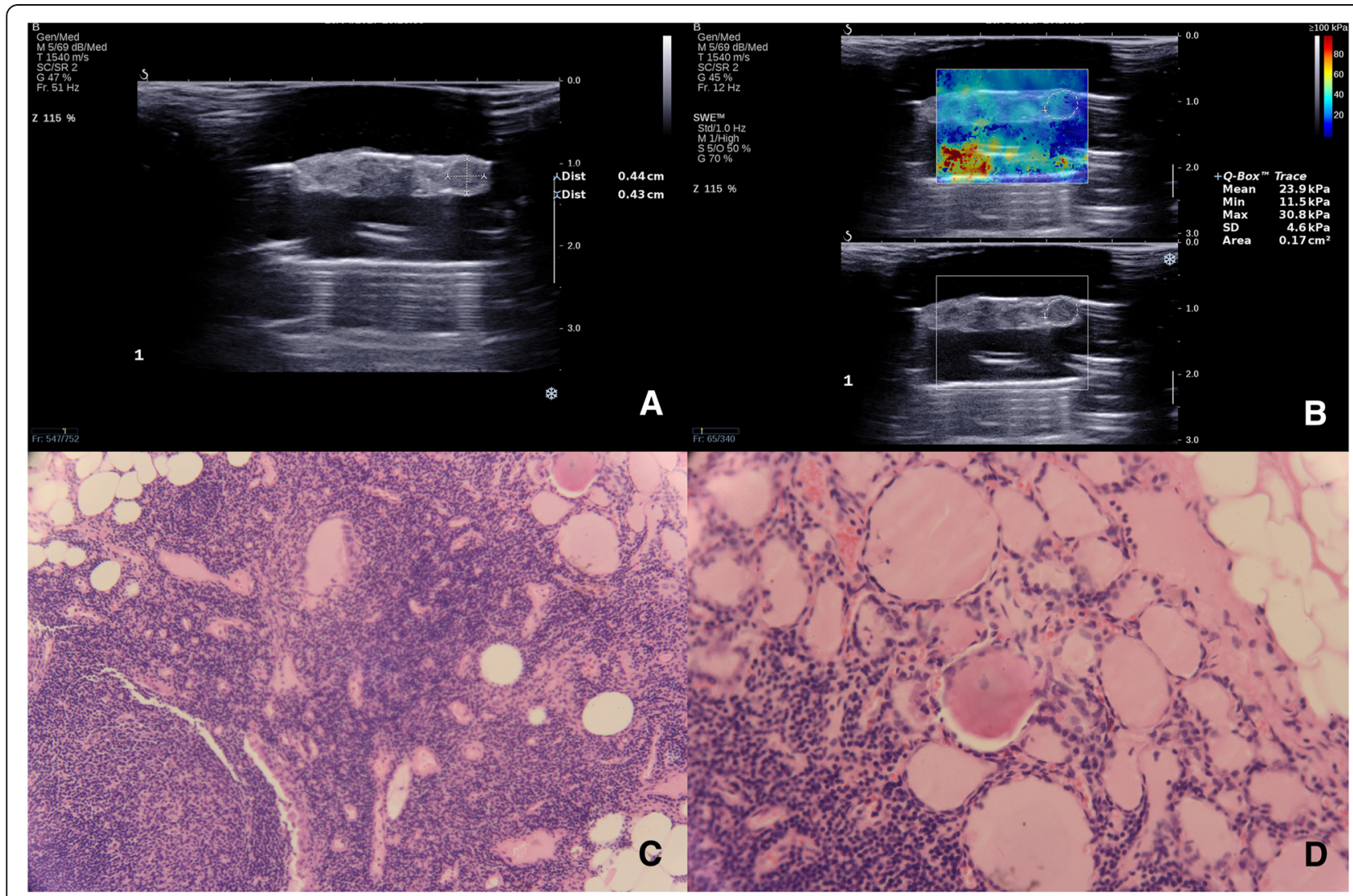

Fig. 2 A 61-year-old man with papillary thyroid carcinoma in the right lobe of thyroid. The long diameter and short diameter of one lymph node at ipsilateral level $\mathrm{VI}$ were $4.4 \mathrm{~mm}$ and $4.3 \mathrm{~mm}$ (a). S/L ratio was 0.977 . $\mathrm{E}_{\text {mean, }} \mathrm{E}_{\max }$ and $\mathrm{E}_{\mathrm{SD}}$ were $23.9 \mathrm{kPa}, 30.8 \mathrm{kPa}$ and $4.6 \mathrm{kPa}$ respectively (b). Gray-ultrasound score and combination score were 2 and 5 respectively. This lymph node was confirmed to be metastatic by pathological diagnosis (c, original magnification $\times 40$, and $\mathbf{d}$, original magnification $\times 100$ ) 


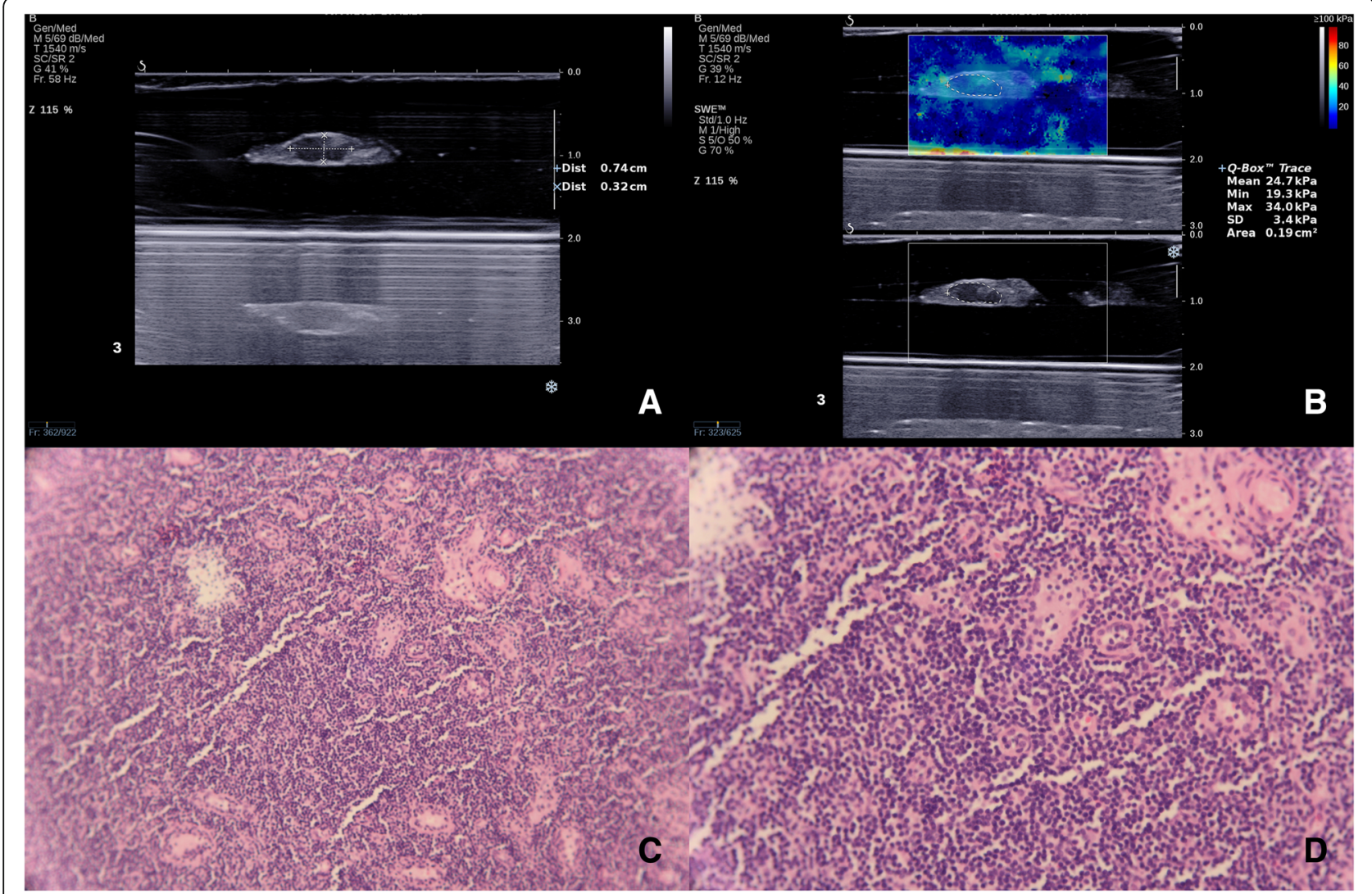

Fig. 3 A 54-year-old woman with papillary thyroid microcarcinoma in the left lobe. The long diameter and short diameter of one lymph node at ipsilateral level VI were $4.1 \mathrm{~mm}$ and $2.1 \mathrm{~mm}(\mathbf{a})$. S/L ratio was 0.512. $E_{\text {mean, }} E_{\max }$ and $E_{S D}$ were $18.0 \mathrm{kPa}, 23.1 \mathrm{kPa}$ and $2.9 \mathrm{kPa}$ respectively (b). Gray-ultrasound score and combination score were 0 and 0 respectively. This lymph node was confirmed to be non-metastatic by pathological diagnosis (c, original magnification $\times 40$, and $\mathbf{d}$, original magnification $\times 100$ )

calculating Youden index. Comprehensive scores of grayscale ultrasound, SWE and combination of them were also analyzed by ROC curve. Intraoperative frozen section results were considered as reference standard to calculate the sensitivity, specificity and area under the curve (AUC) of different diagnostic methods.

\section{Results}

Pathological diagnosis

Pathological diagnosis showed that there were 70 non-metastatic lymph nodes and 17 metastatic lymph nodes in all. Among all lymph nodes, 56 non-metastatic lymph nodes and 17 metastatic lymph nodes were from patients without Hashimoto's thyroiditis. 22.7\% (5/22) patients have level VI lymph nodes metastases, including 4 patients with PTC and 1 patient with PTMC.

Ultrasound performance of metastatic and non-metastatic lymph nodes

\section{Performance of gray-scale ultrasound}

Among the three gray-scale ultrasound indexes, short diameter and $\mathrm{S} / \mathrm{L}$ ratio were significantly different between metastatic and non-metastatic level VI lymph nodes both in all patients and in patients without Hashimoto's thyroiditis (Table 1). Long diameter was not significant in differentiation between metastatic and non-metastatic level VI lymph nodes.

\section{Performance of SWE}

In all patients, two SWE indexes, $E_{\max }$ and $E_{S D}$, were significant in the differentiation of metastatic and non-metastatic level VI lymph nodes (Table 2). In patients without Hashimoto's thyroiditis, in addition to the $E_{\max }$ and $E_{S D}$, the SWE index of $E_{\text {mean }}$ was also significant (Table 2).

\section{Diagnostic values of significant indexes and different} diagnostic methods

The best cutoff values of short diameter, S/L ratio, $E_{\max }$ and $E_{S D}$ were $2.55 \mathrm{~mm}, 0.605,29.20 \mathrm{kPa}$ and $3.45 \mathrm{kPa}$ respectively for all patients, $2.55 \mathrm{~mm}, 0.605$, $25.65 \mathrm{kPa}$ and $3.45 \mathrm{kPa}$ respectively for patients without Hashimoto's thyroiditis (Table 3). The best cutoff value of $E_{\text {mean }}$ in patients without Hashimoto's 


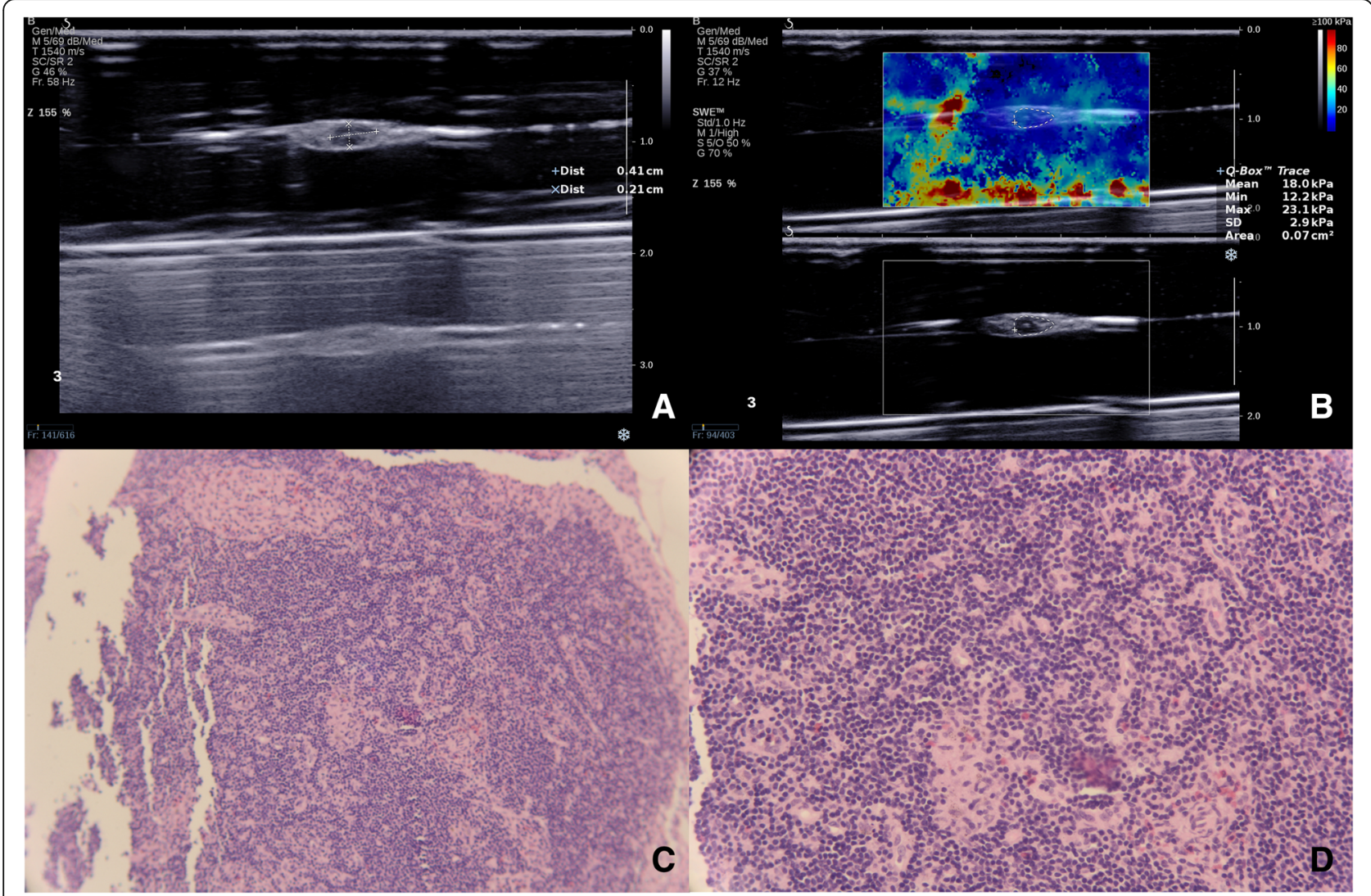

Fig. 4 A 40-year-old woman with papillary thyroid microcarcinoma in the right lobe coexisted with Hashimoto's thyroiditis. The long diameter and short diameter of one lymph node at ipsilateral level VI were $7.4 \mathrm{~mm}$ and $3.2 \mathrm{~mm}(\mathbf{a}) . \mathrm{S} / \mathrm{L}$ ratio was 0.432 . $\mathrm{E}_{\max }$ and $\mathrm{E}_{\mathrm{SD}}$ were $34.0 \mathrm{kPa}$ and $3.4 \mathrm{kPa}$ respectively (b). Gray-ultrasound score and combination score were 1 and 2 respectively. This lymph node was confirmed to be nonmetastatic by pathological diagnosis ( $\mathbf{c}$, original magnification $\times 40$, and $\mathbf{d}$, original magnification $\times 100$ )

thyroiditis was $21.15 \mathrm{kPa}$ (Table 3). The AUC of $\mathrm{E}_{\mathrm{SD}}$ was higher than that of other SWE indexes.

The AUC of combination method was higher than the AUC of gray-scale ultrasound both in all patients $(0.887$ vs. 0.841$)$ and in patients without Hashimoto's thyroiditis (0.925 vs. 0.866). The AUC of each diagnostic method in patients without Hashimoto's thyroiditis was higher than that in all patients (Table 4).

\section{Discussion}

PTC tends to involve cervical lymph nodes with the incidence of metastases ranges from 20 to $90 \%$ [13]. In our study, the incidence of level VI lymph nodes metastases was $22.7 \%$ in all. The low incidence of metastases might result from more PTMC enrolled in our study. PTMC, which is defined by the World Health Organization (WHO) as a PTC $1.0 \mathrm{~cm}$ or smaller in its maximal

Table 1 Gray-scale ultrasound performance of central cervical lymph nodes

\begin{tabular}{|c|c|c|c|c|c|c|c|}
\hline \multirow{2}{*}{ Indexes } & \multirow{2}{*}{$\begin{array}{l}\text { Pathological } \\
\text { Results }\end{array}$} & \multicolumn{3}{|c|}{ All patients } & \multicolumn{3}{|c|}{ Patients without Hashimoto's thyroiditis } \\
\hline & & Number & mean $\pm S d$ & $p$ & Number & mean $\pm S d$ & $p$ \\
\hline \multirow[t]{2}{*}{ Long diameter (mm) } & $(+)$ & 17 & $4.31 \pm 1.20$ & 0.739 & 17 & $4.31 \pm 1.20$ & 0.621 \\
\hline & $(-)$ & 70 & $4.43 \pm 2.02$ & & 56 & $4.07 \pm 1.84$ & \\
\hline \multirow[t]{2}{*}{ Short diameter (mm) } & $(+)$ & 17 & $3.01 \pm 1.16$ & 0.009 & 17 & $3.01 \pm 1.16$ & 0.002 \\
\hline & $(-)$ & 70 & $2.14 \pm 0.81$ & & 56 & $1.93 \pm 0.58$ & \\
\hline \multirow[t]{2}{*}{$S / L$ ratio } & $(+)$ & 17 & $0.70 \pm 0.21$ & 0.003 & 17 & $0.70 \pm 0.21$ & 0.003 \\
\hline & $(-)$ & 70 & $0.52 \pm 0.13$ & & 56 & $0.52 \pm 0.14$ & \\
\hline
\end{tabular}

The pathological result of (+) means metastatic and (-) means non-metastatic. Boldface indicates that $p$ value is statistically significant 
Table 2 SWE performance of central cervical lymph nodes

\begin{tabular}{|c|c|c|c|c|c|}
\hline \multirow[t]{2}{*}{ indexes } & \multirow{2}{*}{$\begin{array}{l}\text { Pathological } \\
\text { Results }\end{array}$} & \multicolumn{2}{|l|}{ All patients } & \multicolumn{2}{|c|}{ Patients without Hashimoto's thyroiditis } \\
\hline & & mean $\pm S d$ & $p$ & mean $\pm S d$ & $p$ \\
\hline \multirow[t]{2}{*}{$E_{\text {mean }}(\mathrm{kPa})$} & $(+)$ & $22.97 \pm 7.75$ & 0.197 & $22.97 \pm 7.75$ & 0.030 \\
\hline & $(-)$ & $19.87 \pm 9.03$ & & $17.88 \pm 8.44$ & \\
\hline \multirow[t]{2}{*}{$\mathrm{E}_{\min }(\mathrm{kPa})$} & $(+)$ & $13.29 \pm 8.41$ & 0.433 & $13.29 \pm 8.41$ & 0.809 \\
\hline & $(-)$ & $14.88 \pm 7.25$ & & $13.80 \pm 7.44$ & \\
\hline \multirow[t]{2}{*}{$\mathrm{E}_{\max }(\mathrm{kPa})$} & $(+)$ & $32.72 \pm 10.21$ & 0.016 & $32.72 \pm 10.21$ & $<0.001$ \\
\hline & $(-)$ & $25.08 \pm 11.80$ & & $21.98 \pm 9.85$ & \\
\hline \multirow[t]{2}{*}{$\mathrm{E}_{\mathrm{SD}}(\mathrm{kPa})$} & $(+)$ & $4.75 \pm 2.83$ & 0.006 & $4.75 \pm 2.83$ & 0.001 \\
\hline & $(-)$ & $2.55 \pm 1.81$ & & $2.10 \pm 1.44$ & \\
\hline
\end{tabular}

The pathological result of $(+)$ means metastatic and (-) means non-metastatic. Boldface indicates that $p$ value is statistically significant

diameter, has lower incidence of metastases than tumors that size was more than $1.0 \mathrm{~cm}[13,14]$. Although ultrasound did not detect all the lymph nodes that were dissected in present study, the number of non-metastatic lymph nodes was 4 times that of metastatic lymph nodes (70 vs. 17) in present study, which was similar to previous study [15].

High-resolution ultrasound has been widely applied to the preoperative evaluation of cervical lymph nodes and it might be the best methodology for determining subsequent surgical treatment of cervical lymph nodes in patients with PTC [16]. Nodal size has always been used as an ultrasound indicator to differentiate the benign and malignant cervical lymph nodes [17]. In our study, the results demonstrated that metastatic level VI lymph nodes had longer short diameters than non-metastatic lymph nodes both in all patients $(p=0.009)$ and in patients without Hashimoto's thyroiditis $(p=0.002)$. Level VI lymph nodes were much smaller than lateral lymph nodes [10]. Therefore, the cutoff value of size in level VI might be different from others. In previous studies, $5 \mathrm{~mm}$ was used as the best cutoff value of level VI lymph nodes in vivo and had low sensitivity [14]. The best cutoff value of short diameter in our study was $2.55 \mathrm{~mm}$ that was much smaller than previous in vivo studies, which might result from much more small lymph nodes detected in condition of ex vivo. The sensitivity of short diameter was moderate. S/L ratio was the other significant gray-scale index in our study and the best cutoff value was 0.605 . Shape of lymph nodes tended to be round when the S/L ratio became larger. And round shape had been proved to be an indicator of malignant cervical lymph nodes $[18,19]$. Previous studies also used other indicators such as echogenicity, microcalcification, nodal vascularity and so on to evaluate cervical lymph nodes $[15,20]$. However, the lymph nodes detected in our study were too small to accurately observe other features. Besides, the vascularity could not be detected due to ex vivo condition. Combining two significant indexes of short diameter and S/L ratio, gray-scale ultrasound had low sensitivity $(52.9 \%)$ and high specificity $(98.6 \%)$ in all patients, which was similar to previous studies [21, 22]. In patients without Hashimoto's thyroiditis, gray-scale ultrasound had high sensitivity $(88.2 \%)$ and moderate specificity $(67.9 \%)$.

Table 3 Diagnostic performance of each significant index

\begin{tabular}{|c|c|c|c|c|c|c|c|}
\hline & \multirow[t]{2}{*}{ Indexes } & \multirow{2}{*}{$\begin{array}{l}\text { Cutoff } \\
\text { value }\end{array}$} & \multirow[t]{2}{*}{ AUC } & \multirow{2}{*}{$\begin{array}{l}\text { Sensitivity } \\
(\%)\end{array}$} & \multirow{2}{*}{$\begin{array}{l}\text { Specificity } \\
(\%)\end{array}$} & \multicolumn{2}{|l|}{ score } \\
\hline & & & & & & 0 & 1 \\
\hline \multirow[t]{4}{*}{ All patients } & Short diameter(mm) & 2.55 & 0.729 & 64.7 & 78.6 & $<2.55$ & $\geq 2.55$ \\
\hline & $\mathrm{S} / \mathrm{L}$ ratio & 0.605 & 0.772 & 76.5 & 80.0 & $<0.605$ & $\geq 0.605$ \\
\hline & $\mathrm{E}_{\max }(\mathrm{kPa})$ & 29.20 & 0.705 & 70.6 & 71.4 & $<29.2$ & $\geq 29.2$ \\
\hline & $E_{S D}(k P a)$ & 3.45 & 0.767 & 70.6 & 84.3 & $<3.45$ & $\geq 3.45$ \\
\hline \multirow{5}{*}{$\begin{array}{l}\text { Patients without Hashimoto's } \\
\text { thyroiditis }\end{array}$} & Short diameter(mm) & 2.55 & 0.783 & 64.7 & 91.0 & $<2.55$ & $\geq 2.55$ \\
\hline & $S / L$ ratio & 0.605 & 0.769 & 76.5 & 76.8 & $<0.605$ & $\geq 0.605$ \\
\hline & $\mathrm{E}_{\text {mean }}(\mathrm{kPa})$ & 21.15 & 0.690 & 76.5 & 73.2 & $<21.15$ & $\geq 21.15$ \\
\hline & $\mathrm{E}_{\max }(\mathrm{kPa})$ & 25.65 & 0.779 & 76.5 & 76.8 & $<25.65$ & $\geq 25.65$ \\
\hline & $\mathrm{E}_{\mathrm{SD}}(\mathrm{kPa})$ & 3.45 & 0.822 & 70.6 & 91.1 & $<3.45$ & $\geq 3.45$ \\
\hline
\end{tabular}


Table 4 Diagnostic performance of gray-scale ultrasound and combination method

\begin{tabular}{llllll}
\hline & Methods & $\begin{array}{l}\text { Best cutoff } \\
\text { value }\end{array}$ & Sensitivity (\%) & Specificity (\%) & AUC \\
\hline All patients & Gray-scale ultrasound & 1.5 & 52.9 & 98.6 & 0.841 \\
& Combination method & 1.5 & 82.4 & 77.1 & 0.887 \\
Patients without Hashimoto's & Gray-scale ultrasound & 0.5 & 88.2 & 67.9 & 0.866 \\
thyroiditis & Combination method & 1.5 & 94.1 & 76.8 & 0.925 \\
\hline
\end{tabular}

SWE can quantitatively measure tissue elasticity and has been confirmed to be a good complementary tool with high diagnostic accuracy for head and neck lymph nodes, especially for sub-centimeter cervical lymph nodes $[8,9]$. In our study, metastatic level VI had higher $\mathrm{E}_{\max }(p=0.016)$ and $\mathrm{E}_{\mathrm{SD}}(p=0.006)$ in all patients. In patients without Hashimoto's thyroiditis, metastatic level VI lymph nodes had higher $\mathrm{E}_{\text {mean }}(0.030), \mathrm{E}_{\max }$ $(p<0.001)$ and $\mathrm{E}_{\mathrm{SD}}(p=0.001)$ (Figs. 2 and 3). Previous studies used $E_{\max }$ to evaluate cervical lymph nodes considering that $E_{\max }$ might reflect the heterogeneous histology better than $E_{\text {mean }}$ and the other indexes $[9,23]$. Higher $E_{\text {mean }}$ had also been used as an indicator of malignant cervical lymph nodes while it had low sensitivity [24]. However, $\mathrm{E}_{\mathrm{SD}}$ had never been used as an indicator. In our study, we found that $\mathrm{E}_{\mathrm{SD}}$ had the highest AUC among all SWE indexes both in all patients (0.767) and patients without Hashimoto's thyroiditis (0.822). The present study confirmed that metastatic lymph nodes were stiffer than non-metastatic and that $\mathrm{E}_{\mathrm{SD}}$ might be the best SWE index for the evaluation of level VI lymph nodes. Higher $\mathrm{E}_{\mathrm{SD}}$ in metastatic lymph nodes might be caused by more heterogeneous components contained in them such as microcalcification, necrosis and cystic changes [19]. The sensitivity of individual index alone was not high. Combining all significant SWE indexes with significant gray-scale ultrasound indexes, combination method had higher AUC than gray-scale in all patients (0.887 vs. 0.841$)$. In patients without Hashimoto's thyroiditis, combination method improved the diagnostic sensitivity $(94.1 \%$ vs. $88.2 \%)$, specificity $(76.8 \%$ vs. $67.9 \%)$ and AUC (0.925 vs. 0.866$)$ when compared with gray-scale ultrasound. In general, our study demonstrated that SWE might provide additional information to help the evaluation of level VI lymph nodes in patients with PTC, which was similar to the results of previous studies [25].

Hashimoto's thyroiditis, which is also called chronic autoimmune thyroiditis, may be a negative predictive factor for level VI lymph nodes metastases in patients with PTC [26, 27]. In our study, 14 level VI lymph nodes in 3 patients with coexistence of PTC and Hashimoto's thyroiditis were all non-metastatic. Hashimoto's thyroiditis may influences the features of cervical lymph nodes [28] and previous study had demonstrated that the diagnostic performance of ultrasound for level VI lymph nodes metastases was lower in PTC with Hashimoto's thyroiditis than that in PTC without Hashimoto's thyroiditis [12]. In present study, we analyzed all indexes and different diagnostic methods respectively in all patients and patients without Hashimoto's thyroiditis and found that the AUCs of short diameter (0.783 vs. 0.729), $E_{\max }(0.779$ vs. 0.705$)$ and $E_{S D}(0.822$ vs. 0.767$)$ were all higher in patients without Hashimoto's thyroiditis. The AUCs of gray-scale ultrasound (0.866 vs. 0.841$)$ and combination method ( 0.925 vs. 0.887 ) were all higher in patients without Hashimoto's thyroiditis than that in all patients. Our study indicated that the Hashimoto's thyroiditis might influence the diagnostic performance of both gray-scale ultrasound and SWE for level VI lymph nodes in patients with PTC (Fig. 4) and that diagnostic performance of ultrasound and SWE might higher in patients without Hashimoto's thyroiditis.

This study had several limitations. First, the sample was small because the acquisition of surgical specimens before rapid frozen section was difficult. Present study showed the potential value of SWE in the assessment of level VI lymph nodes. However, large sample studies are needed to confirm the results further. Second, our study was performed in the condition of ex vivo which could not completely represent the condition in vivo. However, it could unify the surrounding environment and made the ultrasound imaging and results more accurate and reliable. Clinical studies in vivo are still essential and in progress. Third, measurements were performed by one radiologist, and inter-observer and intra-observer variations were not estimated in our study. However, SWE had been proved to have high reproducibility [9]. Therefore, it may not impact the final results. What's more, due to the limitation of ex-vivo condition, only three gray-scale ultrasound parameters were included, which might miss some important characteristics. Methods should be optimized in subsequent in-vivo researches. Besides, our study showed that the diagnostic performance of gray-scale ultrasound and SWE for level VI lymph nodes metastases in PTC tended to be better in patients without Hashimoto's thyroiditis. Studies should be performed in the future focusing on the influence of Hashimoto's thyroiditis to the ultrasound features of metastatic cervical lymph nodes in PTC. 


\section{Conclusion}

Our study demonstrated that shear wave elastography can provide additional information to help ultrasound evaluation of level VI lymph nodes in papillary thyroid carcinoma, especially in papillary thyroid carcinoma without Hashimoto's thyroiditis.

\author{
Abbreviations \\ ATA: American Thyroid Association; AUC: Area Under the Curve; \\ PTC: Papillary Thyroid Carcinoma; PTMC: Papillary Thyroid Microcarcinoma; \\ ROC curve: Receiver Operating Characteristic; S/L ratio: Short-to-Long \\ diameter ratio; SWE: Shear Wave Elastography
}

\section{Acknowledgements}

We thank Jiang Jianwei for preparing the illustrations and everyone who has given us help during our research.

\section{Funding}

This study was sponsored by Natural Science Foundation of Shanghai (grant number 18ZR1434800). This funding body provided financial and technical support during the whole research process and manuscript submission.

\section{Availability of data and materials}

The datasets used and/or analysed during the current study are available from the corresponding author on reasonable request.

\section{Authors' contributions}

CW and TL collected and analysed the ultrasound images; LC and WM analysed the results of rapid frozen section intraoperative; CM put forward the study concepts and designed experiment. All authors have read and approved the manuscript.

\section{Ethics approval and consent to participate}

This study was approved by the Independent Ethics Committee of Shanghai Tongren Hospital. All patients provided their written informed consent prior to enrolling in the study.

\section{Consent for publication}

Not applicable.

\section{Competing interests}

The authors declare that they have no competing interests.

\section{Publisher's Note}

Springer Nature remains neutral with regard to jurisdictional claims in published maps and institutional affiliations.

\section{Author details}

${ }^{1}$ Department of Diagnostic Ultrasound, Tong Ren Hospital, Shanghai Jiao Tong University School of Medicine, No. 1111 Xian Xia Road, Shanghai 200336, China. ${ }^{2}$ Department of Pathology, Rui Jin Hospital, Shanghai Jiao Tong University School of Medicine, No. 197 Rui Jin 2nd Road, Shanghai 200025, China

Received: 13 April 2018 Accepted: 3 October 2018

Published online: 20 October 2018

\section{References}

1. Siegel RL, Miller KD, Jemal A. Cancer statistics, 2017. CA Cancer J Clin. 2017; 67(1):7-30.

2. Cabanillas ME, McFadden DG, Durante C. Thyroid cancer. Lancet. 2016; 388(10061):2783-95

3. Scheumann GF, Gimm O, Wegener G, Hundeshagen $H$, Dralle H. Prognostic significance and surgical management of locoregional lymph node metastases in papillary thyroid cancer. World J Surg. 1994;18(4):559-67 discussion 567-558.

4. Lan X, Sun W, Zhang H, Dong W, Wang Z, Zhang T. A meta-analysis of central lymph node metastasis for predicting lateral involvement in papillary thyroid carcinoma. Otolaryngol Head Neck Surg. 2015;153(5):731-8.
5. Haugen BR, Alexander EK, Bible KC, Doherty GM, Mandel SJ, Nikiforov YE, Pacini F, Randolph GW, Sawka AM, Schlumberger M, et al. 2015 American Thyroid Association management guidelines for adult patients with thyroid nodules and differentiated thyroid Cancer: the American Thyroid Association guidelines task force on thyroid nodules and differentiated thyroid Cancer. Thyroid. 2016;26(1):1-133.

6. Mulla M, Schulte KM. The accuracy of ultrasonography in the preoperative diagnosis of cervical lymph node $(\mathrm{LN})$ metastasis in patients with papillary thyroid carcinoma: a meta-analysis. Eur J Radiol. 2012;81(8):1965 author reply 1966.

7. Ito Y, Tomoda C, Uruno T, Takamura Y, Miya A, Kobayashi K, Matsuzuka F, Kuma K, Miyauchi A. Clinical significance of metastasis to the central compartment from papillary microcarcinoma of the thyroid. World J Surg. 2006;30(1):91-9.

8. Suh $\mathrm{CH}$, Choi YJ, Baek JH, Lee JH. The diagnostic performance of shear wave elastography for malignant cervical lymph nodes: a systematic review and meta-analysis. Eur Radiol. 2017;27(1):222-30.

9. Desmots F, Fakhry N, Mancini J, Reyre A, Vidal V, Jacquier A, Santini L, Moulin G, Varoquaux A. Shear wave Elastography in head and neck lymph node assessment: image quality and diagnostic impact compared with B-mode and Doppler ultrasonography. Ultrasound Med Biol. 2016:42(2):387-98.

10. Lee YJ, Kim DW, Park HK, Kim DH, Jung SJ, Oh M, Bae SK. Pre-operative ultrasound diagnosis of nodal metastasis in papillary thyroid carcinoma patients according to nodal compartment. Ultrasound Med Biol. 2015;41(5): 1294-300.

11. Wu LM, Gu HY, Qu XH, Zheng J, Zhang W, Yin Y, Xu JR. The accuracy of ultrasonography in the preoperative diagnosis of cervical lymph node metastasis in patients with papillary thyroid carcinoma: a meta-analysis. Eur J Radiol. 2012;81(8):1798-805

12. Yoo YH, Kim JA, Son EJ, Youk JH, Kwak JY, Kim EK, Park CS. Sonographic findings predictive of central lymph node metastasis in patients with papillary thyroid carcinoma: influence of associated chronic lymphocytic thyroiditis on the diagnostic performance of sonography. J Ultrasound Med. 2013:32(12):2145-51.

13. Mulla M, Schulte KM. Central cervical lymph node metastases in papillary thyroid cancer: a systematic review of imaging-guided and prophylactic removal of the central compartment. Clin Endocrinol. 2012;76(1):131-6.

14. Choi YJ, Yun JS, Kook SH, Jung EC, Park YL. Clinical and imaging assessment of cervical lymph node metastasis in papillary thyroid carcinomas. World J Surg. 2010;34(7):1494-9.

15. Roh JL, Park JY, Kim JM, Song CJ. Use of preoperative ultrasonography as guidance for neck dissection in patients with papillary thyroid carcinoma. J Surg Oncol. 2009;99(1):28-31.

16. Morita S, Mizoguchi K, Suzuki M, lizuka K. The accuracy of (18)[F]-fluoro-2deoxy-D-glucose-positron emission tomography/computed tomography, ultrasonography, and enhanced computed tomography alone in the preoperative diagnosis of cervical lymph node metastasis in patients with papillary thyroid carcinoma. World J Surg. 2010;34(11):2564-9.

17. Esen G. Ultrasound of superficial lymph nodes. Eur J Radiol. 2006;58(3):345-59.

18. Liu Z, Zeng W, Liu C, Wang S, Xiong Y, Guo Y, Li X, Sun S, Chen T, Maimaiti $Y$, et al. Diagnostic accuracy of ultrasonographic features for lymph node metastasis in papillary thyroid microcarcinoma: a single-center retrospective study. World J Surg Oncol. 2017;15(1):32.

19. Ahuja AT, Ying M, Ho SY, Antonio G, Lee YP, King AD, Wong KT. Ultrasound of malignant cervical lymph nodes. Cancer Imaging. 2008;8:48-56.

20. Mizrachi A, Feinmesser R, Bachar G, Hilly O, Cohen M. Value of ultrasound in detecting central compartment lymph node metastases in differentiated thyroid carcinoma. Eur Arch Oto-Rhino-Laryngol. 2014;271(5):1215-8.

21. Hwang HS, Orloff LA. Efficacy of preoperative neck ultrasound in the detection of cervical lymph node metastasis from thyroid cancer. Laryngoscope. 2011:121(3):487-91.

22. Khokhar MT, Day KM, Sangal RB, Ahmedli NN, Pisharodi LR, Beland MD, Monchik JM. Preoperative high-resolution ultrasound for the assessment of malignant central compartment lymph nodes in papillary thyroid Cancer. Thyroid. 2015:25(12):1351-4.

23. Choi YJ, Lee JH, Lim HK, Kim SY, Han MW, Cho KJ, Baek JH. Quantitative shear wave elastography in the evaluation of metastatic cervical lymph nodes. Ultrasound Med Biol. 2013;39(6):935-40.

24. Bhatia KS, Cho CC, Tong CS, Yuen EH, Ahuja AT. Shear wave elasticity imaging of cervical lymph nodes. Ultrasound Med Biol. 2012;38(2):195-201. 
25. Jung WS, Kim JA, Son EJ, Youk JH, Park CS. Shear wave elastography in evaluation of cervical lymph node metastasis of papillary thyroid carcinoma: elasticity index as a prognostic implication. Ann Surg Oncol. 2015;22(1):111-6.

26. Kim SS, Lee BJ, Lee JC, Kim SJ, Jeon YK, Kim MR, Huh JE, Mok JY, Kim BH, Kim YK, et al. Coexistence of Hashimoto's thyroiditis with papillary thyroid carcinoma: the influence of lymph node metastasis. Head \& neck. 2011; 33(9):1272-7.

27. Donangelo I, Walts AE, Bresee C, Braunstein GD. Lymphocytic thyroiditis is associated with increased number of benign cervical nodes and fewer central neck compartment metastatic lymph nodes in patients with differentiated thyroid cancer. Endocr Pract. 2016;22(10):1192-8.

28. Brancato D, Citarrella R, Richiusa P, Amato MC, Vetro C, Galluzzo CG. Neck lymph nodes in chronic autoimmune thyroiditis: the sonographic pattern. Thyroid. 2013;23(2):173-7.

Ready to submit your research? Choose BMC and benefit from:

- fast, convenient online submission

- thorough peer review by experienced researchers in your field

- rapid publication on acceptance

- support for research data, including large and complex data types

- gold Open Access which fosters wider collaboration and increased citations

- maximum visibility for your research: over $100 \mathrm{M}$ website views per year

At BMC, research is always in progress.

Learn more biomedcentral.com/submissions 